\title{
Suppression of Rice Blast by Preinoculation with Avirulent Pyricularia oryzae and the Nonrice Pathogen Bipolaris sorokiniana
}

\author{
H. K. Manandhar, H. J. Lyngs Jørgensen, S. B. Mathur, and V. Smedegaard-Petersen
}

First author: Plant Pathology Division, Nepal Agricultural Research Council, P.O. Box 1126, Khumaltar, Lalitpur, Nepal; second and fourth authors: Plant Pathology Section, Department of Plant Biology, The Royal Veterinary and Agricultural University, Thorvaldsensvej 40, DK-1871 Frederiksberg C, Copenhagen, Denmark; and third author: Danish Government Institute of Seed Pathology for Developing Countries, Ryvangs Allé 78, DK-2900 Hellerup, Copenhagen, Denmark.

Accepted for publication 19 March 1998.

\begin{abstract}
Manandhar, H. K., Jørgensen, H. J. L., Mathur, S. B., and SmedegaardPetersen, V. 1998. Suppression of rice blast by preinoculation with avirulent Pyricularia oryzae and the nonrice pathogen Bipolaris sorokiniana. Phytopathology 88:735-739.

Avirulent isolates of Pyricularia oryzae and isolates of Bipolaris sorokiniana, a nonrice pathogen, were used to suppress rice blast caused by $P$. oryzae. In greenhouse experiments, both fungi substantially reduced leaf blast when applied $24 \mathrm{~h}$ or more before the pathogen. B. sorokiniana,

but not avirulent isolates of $P$. oryzae, systemically reduced disease in leaf 5 when applied to whole plants at the four-leaf stage. In field experiments, both fungi were able to reduce neck blast significantly. No increase in grain yield was obtained by using avirulent isolates of $P$. oryzae, whereas five sprays with $B$. sorokiniana from seedling to heading stages increased the grain yield in two of three experiments conducted at two locations in Nepal. The significant increase in yield was observed under high inoculum pressure of $P$. oryzae. Induced resistance is suggested to be involved in the suppression of disease.
\end{abstract}

Rice blast, caused by Pyricularia oryzae Cavara (synonym $P$. grisea Sacc.; teleomorph Magnaporthe grisea (Hebert) Barr), is generally considered to be the most important fungal disease of rice (Oryza sativa L.) because of its widespread distribution and destructiveness (21). A continuous effort has been made to control the disease, especially by using fungicides and breeding cultivars resistant to the disease. Biological control, including induction of host resistance against the disease, also has been attempted since the early 1950s. Both biotic and abiotic agents have been suggested to induce resistance in rice against $P$. oryzae. The biotic agents studied in this respect include avirulent isolates of $P$. oryzae $(3,7,9,13,20,22,27$, 34 ) and elicitors derived from $P$. oryzae $(10,26,35)$. Pseudomonas syringae pv. syringae van Hall has also been reported to induce local (23) and systemic resistance in rice against $P$. oryzae (32).

Although several reports have claimed to have found induced resistance in rice under laboratory conditions, demonstrations in the field are very limited. The objective of this study was to test avirulent isolates of $P$. oryzae and isolates of the nonrice pathogen Bipolaris sorokiniana (Sacc.) Shoemaker under greenhouse and field conditions for ability to suppress rice blast.

\section{MATERIALS AND METHODS}

Fungal isolates and inoculum. $P$. oryzae isolates CP 2071 and CP 2069 were used as biocontrol agents on the rice cultivars Masuli and Taichung-176, respectively. As pathogens, P. oryzae isolates CP 2069 and CP 2070 were used on 'Masuli' and 'Taichung-176', respectively. All $P$. oryzae isolates were isolated from rice seeds from Nepal. Similarly, B. sorokiniana isolates CP 2072, a Nepalese isolate from wheat, and CP 1623, a Danish isolate from barley, were used as biocontrol agents. Isolates of $P$. oryzae were grown

Corresponding author: V. Smedegaard-Petersen; E-mail address: vs@kvl.dk

Publication no. P-1998-0507-01R

(C) 1998 The American Phytopathological Society on oatmeal agar (OMA) (Difco Laboratories, Detroit) under 12-h cycles of darkness and near-UV light (Philips TLD 36W/08; Philips Lighting B.V., Rosendaal, the Netherlands) (11) at $25^{\circ} \mathrm{C}$ for 10 days. $B$. sorokiniana was grown on potato dextrose agar (PDA) (Difco Laboratories) under the same conditions as $P$. oryzae. Inoculum of all isolates was harvested in glass-distilled water by gently scraping the surface of the agar. In greenhouse experiments, the concentrations of $P$. oryzae as biocontrol agent and as pathogen were adjusted to 75,000 and 50,000 conidia per $\mathrm{ml}$ of water, respectively, whereas, in field experiments, the concentrations were adjusted to 100,000 and 75,000 conidia per $\mathrm{ml}$ of water, respectively. The concentrations of $B$. sorokiniana used in greenhouse and field experiments were 30,000 and 40,000 conidia per ml, respectively.

Greenhouse experiments. Greenhouse experiments were conducted at the Royal Veterinary and Agricultural University, Copenhagen, Denmark, during 1992 to 1993 at 25 to $30^{\circ} \mathrm{C}$ under natural daylight conditions. Two rice cultivars, Taichung-176 (Tsai-YuanChung $\times$ Dee-geo-woo-gen, from Taiwan) and Masuli (Mayang Ebos $80 * 2 \times$ Taichung 65, from Malaysia) were used. Both are susceptible to $P$. oryzae under field conditions in Nepal (16). 'Masuli' was released in Nepal in 1973 and is widely grown in terai (plains) and warm valleys of Nepal. 'Taichung-176' was released in Nepal in 1966 and is one of the most popular rice cultivars in the Kathmandu Valley and surroundings.

About 30 seeds were sown in a row in a 10- by $12-\mathrm{cm}$ plastic pot containing approximately 1 liter of the soil mix Weibulls Enhetsjord (K jord, Svalöf Weibull AB, Hammenhög, Sweden) (11). The pots were arranged in a randomized complete block design with three replications. Ammonium sulfate (1 g) containing 21\% N (Svovlsur ammoniak 21; Kemira Danmark A/S, Vedbæk, Denmark) and $0.1 \mathrm{~g}$ of $13 \%$ iron chelate (Pioner Jernchelat 13\%; P. Brøste A/S, Lyngby, Denmark) were added to the soil mix in each pot as a basal dose of fertilizer through watering when the rice was sown. Iron was added because the iron content of the soil mix was insufficient for the rice plants, which otherwise developed typical iron deficiency symptoms. The plants were fertilized 15 days after seeding with approx- 
imately $1 \mathrm{ml}$ of a complete fertilizer with micronutrients added (i.e., Hornum Næring; P. Brøste Industri A/S, Lyngby, Denmark) and approximately $1 \mathrm{~g}$ of ammonium sulfate per pot. The soil was kept moist throughout the growing period, but not flooded.

The fifth developed leaf of each of 10 rice plants (about 5 weeks old) per pot was fixed with the abaxial side up in a horizontal position on bent plastic plates (6) using unbleached cotton strings. Avirulent $P$. oryzae (isolate CP 2071 on 'Masuli' and CP 2069 on 'Taichung-176') and B. sorokiniana (CP 1623) were used as biocontrol agents. The leaves were inoculated with the biocontrol agent 12,24 , and $48 \mathrm{~h}$ prior to inoculation with the pathogen. A 1:1 mixture of biocontrol agent and pathogen represented the 0-h control. Inoculum of the biocontrol agent was removed (except for $0 \mathrm{~h}$ ) by gently wiping the inoculated leaves towards the tip with wet cotton and then rinsing them with water before inoculation with the pathogen. This technique effectively remove fungal spores (6). To test for a possible systemic protection against disease, whole plants were inoculated with the biocontrol agents at the four-leaf stage (before the fifth leaf started to emerge) and with the pathogen at the five-leaf stage (before the sixth leaf started to emerge). All types of inoculum were sprayed onto the fixed leaves or whole plants until runoff, using a plastic hand sprayer. Inoculated plants were incubated at 25 to $28^{\circ} \mathrm{C}$ under $100 \%$ humidity in plastic bags for $72 \mathrm{~h}$ in darkness. The plants were then exposed to open air in the greenhouse and grown there until assessment of disease. The experiments were repeated three times.

Field experiments. Field experiments were conducted in Nepal at the National Agricultural Research Institute, Khumaltar, Lalitpur, and at the Agricultural Research Station, Rampur, Chitwan, during the summer of 1994. Both are part of the Nepal Agricultural Research Council. Khumaltar is situated in the Kathmandu Valley (midhill, 1,350 $\mathrm{m}$ above sea level) and Rampur is located in the Chitwan Valley (inner terai, $228 \mathrm{~m}$ above sea level). The soil type (33) at Khumaltar is Ustocrept (31\% clay, 55\% silt, and $14 \%$ sand) and Dystrocrept at Rampur (12\% clay, 28\% silt, and 60\% sand). Two field experiments using 'Taichung-176' were conducted at Khumaltar, and one at Rampur using 'Masuli'. Fourweek-old rice seedlings, raised in dry bed, were transplanted (two to three seedlings per hill) in plots of $10 \mathrm{~m}^{2}(2.5$ by $4 \mathrm{~m})$ at a plant distance of 15 by $15 \mathrm{~cm}$. The plots were arranged in a randomized complete block design with four replications. Transplanting was done on 29 June at Khumaltar (experiment 1), 10 August at Rampur (experiment 2), and 3 July at Khumaltar (experiment 3). One day before transplanting, nitrogen was applied as urea $(60 \mathrm{~kg}$ of $\mathrm{N}$ per ha), phosphorus was applied as triple super phosphate (40 kg of $\mathrm{P}$ per ha), and potassium was applied as muriate of potash (30 kg of $\mathrm{K}$ per ha). Furthermore, urea was top-dressed at the rate of $30 \mathrm{~kg}$

TABLE 1 . Severity of leaf blast caused by Pyricularia oryzae on the fifth developed leaves after preinoculation of the same leaves of rice 'Taichung-176' and 'Masuli' with avirulent isolates of P. oryzae or Bipolaris sorokiniana in the greenhouse

\begin{tabular}{lccccc}
\hline & \multicolumn{4}{c}{ Mean leaf blast score $(0 \text { to } 9 \text { scale })^{\mathrm{b}}$} \\
\cline { 2 - 3 } & \multicolumn{2}{c}{ Avirulent $P$. oryzae } & & \multicolumn{2}{c}{ B. sorokiniana } \\
\cline { 2 - 3 } \cline { 5 - 6 } Time $(\mathrm{h})^{\mathrm{a}}$ & 'Taichung 176' & 'Masuli' & & 'Taichung 176' & 'Masuli' \\
\hline $0^{\mathrm{c}}$ & 6.9 & 6.9 & & 6.5 & 6.9 \\
12 & 6.1 & 6.4 & & 5.9 & 6.4 \\
24 & 4.0 & 4.3 & & 3.2 & 3.5 \\
48 & 3.5 & 3.8 & & 2.8 & 3.0 \\
Nontreated control & 7.4 & 7.5 & & 7.3 & 7.7 \\
$P$ value & 0.0001 & 0.0001 & 0.0001 & 0.0001 \\
LSD $_{0.95}$ & 0.4 & 0.3 & & 0.3 & 0.2 \\
\hline
\end{tabular}

a Interval of time between inoculation with avirulent $P$. oryzae (isolate $\mathrm{CP}$ 2071 on 'Masuli' and isolate CP 2069 on 'Taichung-176') or B. sorokiniana (isolate CP 1623) and inoculation with virulent P. oryzae (isolate CP 2069 on 'Masuli' and isolate CP 2070 on 'Taichung-176').

b Data are means of three replications (10 leaves per replication).

c $1: 1$ mixure of both fungi. of $\mathrm{N}$ per ha at the tillering and heading stages after hand-weeding. All fertilizers were broadcast by hand. The experiment at Rampur was irrigated by flooding three times. The first irrigation took place just before transplanting ( 9 August) and the following two during the tillering and booting stages, respectively. The experiments at Khumaltar were only irrigated during transplanting.

In experiment 1 at Khumaltar and experiment 2 at Rampur, $B$. sorokiniana (isolate CP 2072) and avirulent $P$. oryzae (i.e., isolate CP 2069 at Khumaltar and isolate CP 2071 at Rampur, respectively) were used. In addition, both experiments included the fungicide edifenphos (Hinosan 50 EC, 2 ml/liter of water; Bayer (India) Limited, Bombay, India), commonly used in Nepal for control of rice blast (19). Each plot received five sprays during the growing season with the biocontrol agents or fungicide. Thus, the treatments were carried out at seedling (growth stage [GS] 2) (2), tillering (GS 3), stem elongation (GS 4), booting (GS 5), and heading (GS 6) stages. The dates of applications were 21 June, 5 August, 21 August, 7 September, and 24 September at Khumaltar, respectively; and 1 August, 13 September, 2 October, 18 October, and 5 November at Rampur, respectively. In experiment 3 at Khumaltar, the biocontrol agents $B$. sorokiniana (isolate $\mathrm{CP} 2072$ ) and avirulent $P$. oryzae (isolate CP 2069) were applied in various combinations of growth stages: seedling stage; seedling plus tillering plus stem elongation stages; seedling plus tillering plus stem elongation plus booting plus heading stages; seedling plus booting plus heading stages; tillering plus stem elongation stages; tillering plus stem elongation plus booting plus heading stages; and booting plus heading stages.

The biocontrol agents were inoculated after sunset so that the inoculated plants remained wet until next morning. In experiment 1 at Khumaltar, the rice was inoculated with virulent $P$. oryzae (isolate CP 2070) 3 to 4 days after each application of the biocontrol agents or fungicide. In the two other experiments, disease resulted from natural inoculum.

In all experiments, about 1 liter of inoculum of either biocontrol agent or pathogen and about 0.6 liter of fungicide was applied per plot, using a hand-compression sprayer (Maruti, 9-liter capacity; American Spring \& Pressing Works Pvt. Ltd., Malad, Bombay, India).

Assessment of disease and yield. In the greenhouse experiments, leaf blast was scored 6 to 7 days after inoculation with the pathogen. Each seedling was examined and rated on a 0 to 9 scale according to the international specification for seedling blast in nurseries (2). Systemic disease suppression caused by inoculation of whole plants with biocontrol agents at the four-leaf stage was assessed by comparing the number of susceptible-type blast lesions per leaf (broad, spindle-shaped lesions with yellow, brown, or purple margins) (2) on the fifth leaves of plants with and without prior application of biocontrol agents.

In the field experiments, neck blast was recorded at maturity (GS 9). The neck blast incidence was computed according to the method adopted by the Agriculture Production Bureau, Japan (1).

$$
\% \text { neck blast incidence }=\frac{4 \mathrm{~A}+3 \mathrm{~B}+2 \mathrm{C}+\mathrm{D}+0 \mathrm{E}}{4 \times \text { number of hills examined }}
$$

in which $\mathrm{A}=$ hills for which $61 \%$ or more panicles are found to be infected, B = hills for which 31 to $60 \%$ of panicles are found to be in-

TABLE 2. Number of blast lesions on the fifth leaf of 'Taichung-176' in the greenhouse after preinoculation of the whole plant at the four-leaf stage with an avirulent isolate of Pyricularia oryzae or Bipolaris sorokiniana

\begin{tabular}{lcc}
\hline Treatment & Lesions per leaf $^{\mathrm{a}}$ & ${\text { Decrease }(\%)^{\mathrm{b}}}^{\text {P. oryzae (CP 2069) }}$ \\
\hline B. sorokiniana (CP 1623) & 11.1 & 3.5 \\
Nontreated control (CP 2070) & 6.3 & 45.2 \\
$P$ value & 11.5 & $\ldots$ \\
$\mathrm{LSD}_{0.95}$ & 0.0005 & \\
\hline
\end{tabular}

\footnotetext{
a Average number of blast lesions per leaf counted 5 days after challenge inoculation. Data are means of three replications (10 leaves per replication).

b Percent decrease in lesion number compared with control.
} 
fected, $\mathrm{C}=$ hills for which 11 to $30 \%$ of panicles are found to be infected, $\mathrm{D}=$ hills for which $10 \%$ or less panicles are found to be infected, and $\mathrm{E}=$ hills for which $0 \%$ panicles are found to be infected.

The experiments were harvested on 7 to 10 November at Khumaltar and on 10 to 11 December at Rampur, and grain yield and thousand-grain weight were measured. From each plot, $7.5 \mathrm{~m}^{2}$ was harvested by hand using a sickle, leaving border rows in each side. The grain was threshed using a manual paddy thresher, winnowed by hand winnower, and sun-dried for 2 days. The percentage of moisture was determined using a moisture meter (Osaw Agro moisture meter; The Oriental Science Apparatus Workshop, Haryana, India) and the grain weight calculated at $14 \%$ moisture level.

Disease ratings, grain yield, and thousand-grain weight were analyzed using the GLM procedure in PC-SAS (release 6.11; SAS Institute, Cary, NC).

Dual culture and germination fluid tests. To examine possible antagonistic activity between the biocontrol agents and the pathogens, isolates CP 1623 and CP 2072 of B. sorokiniana and isolates CP 2069 and CP 2070 of $P$. oryzae were grown in dual cultures on PDA plates in all combinations. Dual cultures were also made reciprocally between the $P$. oryzae isolates. Discs (5-mm diameter) from actively growing cultures of $B$. sorokiniana and $P$. oryzae were placed alternately $2.5 \mathrm{~cm}$ apart in a circle (a total of six discs per plate) and replicated in six plates. Each of the test organisms were plated alone as controls. The plates were incubated for 10 days under the same conditions as for inoculum production.

The effect of germination fluid of the biocontrol agents on growth of $P$. oryzae isolates was also tested. Suspensions $(100,000$ conidia per $\mathrm{ml}$ of water) of $B$. sorokiniana or $P$. oryzae were incubated in darkness at $25^{\circ} \mathrm{C}$ for $12 \mathrm{~h}$, filtered through filter paper, and finally through a sterile millipore filter with $0.45-\mu \mathrm{m}$ pore size (Minisart NML, 165 55K; Sartorius AG, Göttingen, Germany). The fluid $(100 \mu \mathrm{l})$ was spread on the agar surface of plates containing $15 \mathrm{ml}$ of OMA. Six discs of $P$. oryzae isolates were placed on each plate. There were six replications. As controls, each $P$. oryzae isolate was transferred to OMA plates without germination fluid. The plates were incubated for 10 days as described before.

\section{RESULTS}

In incompatible interactions between avirulent isolates of $P$. oryzae and rice, the fungus produced small necrotic resistant-type blast lesions, less than $0.5 \mathrm{~mm}$ in diameter, 60 to $72 \mathrm{~h}$ after inoculation. The two isolates of $B$. sorokiniana caused small necrotic lesions less than $1 \mathrm{~mm}$ in diameter on both 'Taichung-176' and 'Masuli' within $24 \mathrm{~h}$ after inoculation. At high temperature (28 to $30^{\circ} \mathrm{C}$ ) and high humidity, the lesions enlarged up to about $1.5 \mathrm{~mm}$ in diameter, but sporulation never occurred. B. sorokiniana produced more lesions than did avirulent isolates of $P$. oryzae (data not shown).

TABLE 3. Suppression of blast in the field at Khumaltar on 'Taichung-176' using foliar sprays of an avirulent isolate of Pyricularia oryzae, an isolate of Bipolaris sorokiniana, and the fungicide Hinosan

\begin{tabular}{lcccc}
\hline Treatment $^{\mathrm{a}}$ & $\begin{array}{c}\text { Incidence } \\
(\%)^{\mathrm{b}}\end{array}$ & $\begin{array}{c}\text { Reduction } \\
(\%)^{\mathrm{c}}\end{array}$ & $\begin{array}{c}\text { Yield } \\
(\mathrm{kg} / \mathrm{ha})\end{array}$ & $\begin{array}{c}\text { Increase } \\
(\%)^{\mathrm{d}}\end{array}$ \\
\hline P. oryzae (CP 2069) & 41.7 & 20.3 & 3496 & 5.6 \\
B. sorokiniana $(\mathrm{CP} 2072)$ & 36.5 & 30.2 & 3661 & 10.6 \\
Hinosan & 19.5 & 62.7 & 4084 & 23.4 \\
Nontreated control & 52.3 & $\ldots$ & 3310 & $\ldots$ \\
$P$ value & 0.0001 & & \multicolumn{3}{c}{0.0001} & \\
LSD $_{0.95}$ & 6.9 & \multicolumn{3}{c}{201} \\
\hline
\end{tabular}

a The biocontrol agents and the fungicide were applied five times, i.e., at seedling, tillering, stem elongation, booting, and heading stages.

b Percent neck blast incidence. All plants were inoculated with virulent $P$. oryzae 3 to 4 days after each application of biocontrol agent or fungicide.

c Percent reduction of disease compared with nontreated control.

d Percent increase in grain yield compared with nontreated control.
In the greenhouse, preinoculation of rice with avirulent $P$. oryzae or $B$. sorokiniana prior to inoculation with virulent $P$. oryzae significantly reduced the leaf blast severity compared with the nontreated control at all treatment times (Table 1). The disease reduction increased with increasing time between application of the biocontrol agents and the pathogen. Hence, at an interval of $48 \mathrm{~h}$ between inoculations, avirulent $P$. oryzae and $B$. sorokiniana reduced the leaf blast scores from 7.4 to 3.5 and from 7.3 to 2.7 , respectively, on 'Taichung-176' compared with the nontreated control. On 'Masuli', the corresponding reductions were from 7.5 to 3.8 and from 7.7 to 3.0 for avirulent $P$. oryzae and $B$. sorokiniana, respectively.

Disease was suppressed in the fifth leaves of 'Taichung-176' when the whole plant was inoculated at the four-leaf stage with $B$. sorokiniana, 15 days before inoculation with $P$. oryzae (Table 2). Hence, the number of blast lesions was reduced by $45 \%$ on fifth leaves compared with the nontreated control. Disease was not reduced significantly when using avirulent $P$. oryzae as the biocontrol agent.

Neck blast incidence in field experiment 1 at Khumaltar (Table 3), where the plants were inoculated with virulent $P$. oryzae, averaged $52 \%$ in nontreated control plots. In experiment 2 at Rampur (Table 4) and experiment 3 at Khumaltar (Table 5), where plants were not inoculated, the neck blast incidence in the nontreated control plots was about 80 and 21 to $22 \%$, respectively.

Avirulent isolates of $P$. oryzae reduced neck blast incidence significantly in all three experiments (Tables 3 to 5). Disease reductions were $20 \%$ in experiment 1 at Khumaltar (Table 3) and $26 \%$ in the corresponding experiment at Rampur (Table 4). In experiment 3 at Khumaltar (Table 5), disease incidence was reduced significantly when avirulent $P$. oryzae isolates were applied at both booting and heading stages (Table 5), but grain yield (Tables 3 to 5) and thousand-grain weight (data not shown) were not significantly increased in any of the experiments.

B. sorokiniana significantly reduced neck blast incidence and increased the grain yield both in experiment 1 at Khumaltar (Table 3 ) and in experiment 2 at Rampur (Table 4). The percent reduction in disease was $30 \%$ at Khumaltar and $42 \%$ at Rampur compared with the nontreated controls. Similarly, grain yield was significantly increased by $11 \%$ at Khumaltar (Table 3) and $16 \%$ at Rampur (Table 4). In experiment 3 at Khumaltar (Table 5), with the exception of treatment 4 , significant control of the disease occurred only in treatments involving application of B. sorokiniana at both booting and heading stages. There was, however, no effect on grain yield. Thousand-grain weight was not increased in any of the three experiments (data not shown).

At both Khumaltar and Rampur (Tables 3 and 4), the effect of edifenphos was greater than that of avirulent isolates of $P$. oryzae and $B$. sorokiniana in reducing disease and increasing grain yield.

In dual culture experiments, no zones of inhibition were formed in any of the combinations between $B$. sorokiniana and $P$. oryzae or between different $P$. oryzae isolates. After 10 days, B. sorokini-

TABLE 4. Suppression of blast in the field at Rampur on 'Masuli' using foliar sprays of an avirulent isolate of Pyricularia oryzae, an isolate of Bipolaris sorokiniana, and the fungicide Hinosan

\begin{tabular}{lcccc}
\hline Treatment $^{\mathrm{a}}$ & $\begin{array}{c}\text { Incidence } \\
(\%)^{\mathrm{b}}\end{array}$ & $\begin{array}{c}\text { Reduction } \\
(\%)^{\mathrm{c}}\end{array}$ & $\begin{array}{c}\text { Yield } \\
(\mathrm{kg} / \mathrm{ha})\end{array}$ & $\begin{array}{c}\text { Increase } \\
(\%)^{\mathrm{d}}\end{array}$ \\
\hline P. oryzae (CP 2071) & 58.9 & 26.1 & 2909 & 6.7 \\
B. sorokiniana (CP 2072) & 46.1 & 42.2 & 3150 & 15.6 \\
Hinosan & 33.6 & 57.8 & 3412 & 25.2 \\
Nontreated control & 79.7 & $\ldots$ & 2726 & $\ldots$ \\
$P$ value & 0.0003 & & 0.0036 & \\
LSD $_{0.95}$ & 14.4 & & 307 &
\end{tabular}

a The biocontrol agents and the fungicide were applied five times, i.e., at seedling, tillering, stem elongation, booting, and heading stages.

b Percent neck blast incidence. Disease resulted from natural inoculum.

c Percent reduction of disease compared with nontreated control.

d Percent increase in grain yield compared with nontreated control. 
ana completely covered the agar surface except for the area occupied by $P$. oryzae, but did not overgrow $P$. oryzae even when the plates were incubated under the same conditions for 1 month. The colony size of $P$. oryzae in dual cultures with $B$. sorokiniana was smaller $(2.1$ to $2.2 \mathrm{~cm})$ than in control plates $(2.7$ to $2.8 \mathrm{~cm})$, whereas, in dual cultures between isolates of $P$. oryzae, colony size of one isolate $(2.6$ to $2.8 \mathrm{~cm}$ ) was not affected by the other. Germination fluids of $B$. sorokiniana and $P$. oryzae did not affect colony size or appearance of $P$. oryzae; the colony size ranged between 2.7 and $2.9 \mathrm{~cm}$.

\section{DISCUSSION}

Both avirulent isolates of $P$. oryzae and the nonrice pathogen $B$. sorokiniana reduced blast significantly under greenhouse conditions when sprayed onto the rice plants prior to inoculation with virulent isolates of $P$. oryzae. Avirulent isolates of $P$. oryzae were previously reported to be able to suppress infection of virulent isolates of the same fungus $(3,7,9,13,20,22,27,34)$. In some of these reports $(3,9,22,27,34)$, induced resistance or induced inaccessibility was suggested to be involved. To our knowledge, B. sorokiniana has not previously been shown to suppress rice blast except in a preliminary report (18). However, Bipolaris spp. have been used as biocontrol agents. Thus, $B$. sorokiniana and B. oryzae were used to control spot blotch caused by B. sorokiniana in wheat (5) and in barley $(24,25)$. Similarly, the severity of brown spot of rice (B. oryzae) was reduced by preinoculation with a conidial suspension or conidial extracts of the same fungus $(8,28-30,36)$. Induced or acquired resistance was suggested to be responsible for the disease reductions observed. Recently, Jørgensen et al. (11) reported the control of Drechslera teres and other pathogens of barley by preinoculation with $B$. maydis. In this investigation, induced resistance was also suggested to be involved.

We found that the effect of the biocontrol agents was greater as the time interval between application of the agents and the pathogen increased. Similar results were reported previously in rice

TABLE 5. Suppression of blast in the field at Khumaltar on 'Taichung 176' using foliar sprays of an avirulent isolate of Pyricularia oryzae and an isolate of Bipolaris sorokiniana

\begin{tabular}{|c|c|c|c|c|}
\hline Treatment $^{\mathrm{a}}$ & $\begin{array}{c}\text { Incidence } \\
(\%)^{\mathrm{b}}\end{array}$ & $\begin{array}{l}\text { Reduction } \\
(\%)^{\mathrm{c}}\end{array}$ & $\begin{array}{l}\text { Yield } \\
\text { (kg/ha) }\end{array}$ & $\begin{array}{c}\text { Increase } \\
(\%)^{\mathrm{d}}\end{array}$ \\
\hline \multicolumn{5}{|l|}{ P. oryzae (CP 2069) } \\
\hline $\mathrm{S}$ & 17.7 & 21.0 & 3,495 & -1.7 \\
\hline $\mathrm{S}+\mathrm{T}+\mathrm{SE}$ & 18.5 & 17.4 & 3,661 & 3.0 \\
\hline $\mathrm{S}+\mathrm{T}+\mathrm{SE}+\mathrm{B}+\mathrm{H}$ & 15.4 & 31.3 & 3,676 & 3.4 \\
\hline $\mathrm{S}+\mathrm{B}+\mathrm{H}$ & 14.3 & 36.2 & 3,561 & 0.2 \\
\hline $\mathrm{T}+\mathrm{SE}$ & 21.6 & 3.6 & 3,658 & 2.9 \\
\hline $\mathrm{T}+\mathrm{SE}+\mathrm{B}+\mathrm{H}$ & 14.3 & 36.2 & 3,688 & 3.8 \\
\hline $\mathrm{B}+\mathrm{H}$ & 14.8 & 33.9 & 3,589 & 1.0 \\
\hline Nontreated control & 22.4 & $\ldots$ & 3,554 & $\ldots$ \\
\hline$P$ value & 0.0475 & & 0.9967 & \\
\hline $\operatorname{LSD}_{0.95}$ & 6.2 & & $\mathrm{~ns}^{\mathrm{e}}$ & \\
\hline \multicolumn{5}{|c|}{ B. sorokiniana $(\mathrm{CP} 2072)$} \\
\hline $\mathrm{S}$ & 21.6 & -4.9 & 3,525 & 0.5 \\
\hline $\mathrm{S}+\mathrm{T}+\mathrm{SE}$ & 18.5 & 10.2 & 3,620 & 3.3 \\
\hline $\mathrm{S}+\mathrm{T}+\mathrm{SE}+\mathrm{B}+\mathrm{H}$ & 13.3 & 35.4 & 3,686 & 5.1 \\
\hline $\mathrm{S}+\mathrm{B}+\mathrm{H}$ & 15.9 & 22.8 & 3,648 & 4.1 \\
\hline $\mathrm{T}+\mathrm{SE}$ & 17.2 & 16.5 & 3,602 & 2.7 \\
\hline $\mathrm{T}+\mathrm{SE}+\mathrm{B}+\mathrm{H}$ & 11.5 & 44.2 & 3,672 & 4.7 \\
\hline $\mathrm{B}+\mathrm{H}$ & 15.1 & 26.7 & 3,639 & 3.8 \\
\hline Nontreated control & 20.6 & $\ldots$ & 3,506 & $\ldots$ \\
\hline$P$ value & 0.0083 & & 0.9944 & \\
\hline $\mathrm{LSD}_{0.95}$ & 5.3 & & ns & \\
\hline
\end{tabular}

a Spraying at stages $\mathrm{S}=$ seedling, $\mathrm{T}=$ tillering, $\mathrm{SE}=$ stem elongation, $\mathrm{B}=$ booting, and $\mathrm{H}=$ heading.

b Percent neck blast incidence. Disease resulted from natural inoculum.

c Percent reduction of disease compared with nontreated control.

${ }^{d}$ Percent increase in grain yield compared with nontreated control.

${ }^{\mathrm{e}} \mathrm{ns}=$ nonsignificant
$(3,9)$ and oilseed rape $(15)$. However, we also found that periods shorter that $24 \mathrm{~h}$, and even coinoculation of biocontrol agents and pathogen, resulted in significant disease reductions. This was previously demonstrated $(9,13,20,34)$. Observations of such inhibition might suggest that antibiosis or nutrient competition was involved in disease suppression. However, dual-culture experiments with $B$. sorokiniana and $P$. oryzae indicated that this was not the case, because the two organisms did not suppress each others' growth on PDA, as indicated by the lack of inhibition zones. The colonies of $P$. oryzae in dual cultures with $B$. sorokiniana were smaller than in control plates, but this was because $B$. sorokiniana grew faster than $P$. oryzae and thus occupied all free space, limiting the growth possibilities of $P$. oryzae. These results were further supported by the observation that growth of $P$. oryzae was not affected by germination fluids of $B$. sorokiniana or other isolates of $P$. oryzae. Even when conidia of $P$. oryzae and $B$. sorokiniana were incubated together in water, germination of the former was not inhibited by the latter (data not shown). For $P$. oryzae, mixing of virulent and avirulent inoculum did not affect germination of the virulent race (20). According to Bell et al. (4), if two organisms each colonizes approximately one-half of the medium surface in dual-culture experiments and neither appears to dominate the other, they are considered nonantagonistic to each other.

On the other hand, the involvement of induced resistance, as defined by Kloepper et al. (14), is strongly suggested by Northern blot analyses showing the accumulation of several defense-related transcripts in the rice leaves following inoculation either with avirulent $P$. oryzae or with $B$. sorokiniana alone (17), indicating that the defense response in the rice is activated. These observations are consistent with findings by Ohata and Kozaka (20), who reported the production of two fluorescent compounds with antifungal properties in rice leaves even when avirulent and virulent $P$. oryzae were inoculated onto the plants at the same time. The compounds were not detected in healthy plants or in $P$. oryzae. Arase and Fujita (3) observed that, in preinoculated leaf sheaths, penetration and hyphal growth of virulent $P$. oryzae in the host cells were inhibited, coinciding with a hyaline-to-pale yellow color previously reported to be related to resistance. In oilseed rape, Mahuku et al. (15) reported systemic induced resistance against a highly virulent isolate of Leptosphaeria maculans when coinoculating it with a weakly virulent isolate of the same fungus.

Although B. sorokiniana protected the rice both locally and systemically, the local effect was stronger than the systemic effect. The systemic protection was not the result of migration of $B$. sorokiniana spores. Light microscopy studies (data not shown) revealed that $B$. sorokiniana was never found on the fifth leaves when inoculated only on the fourth leaves. No systemic protective effect was found in response to an avirulent isolate of $P$. oryzae, and this is in accordance with results from other investigations $(9,13)$. Park and Kim (22), however, found reduced size of lesions produced by virulent $P$. oryzae up to $3 \mathrm{~cm}$ above the site of inoculation with avirulent $P$. oryzae on the same leaf. To our knowledge, systemic protection of rice against $P$. oryzae using a biological agent previously has been reported only by Smith and Métraux (32), who used $P$. syringae pv. syringae; however, Reimmann et al. (23) were unable to duplicate these results.

Having found biocontrol agents with substantial disease-reducing abilities under controlled conditions, the next important step in examination of their effect and potential future applicability is to perform field experiments. In the field, avirulent isolates of $P$. oryzae reduced the neck blast incidence on 'Taichung-176' and 'Masuli' when the plants were sprayed at both booting and heading stages, but the effect on grain yield and thousand-grain weight was not significant in any of the three experiments. Iwano (9) also reported that preinoculation with an avirulent isolate of $P$. oryzae at the tillering or heading stages under field conditions reduced the leaf blast and panicle blast, respectively. 
B. sorokiniana showed greater protection against blast in the field than avirulent isolates of $P$. oryzae. Because there were differences in the disease pressure between the experiments, it is important to consider whether the disease suppression by the biocontrol agents is greater under high (Tables 3 and 4) than under low disease pressure (Table 5). If this is the case, it is an important observation, because under low disease pressure or in the absence of disease, a biocontrol agent based on or involving induced resistance may itself have negative effects on the rice (i.e., host defense reactions are energy consuming and thus yield may be reduced) (31).

The biocontrol agents used in the current experiments could be potential candidates for future development of biological protectants involving induced resistance to be used commercially in rice. A crop like rice is particularly suited for protection by induced resistance, because the plants can be treated with the inducer in several ways before transplanting to the field. However, use of living biocontrol agents may be problematic under field conditions because of high cost and sensitivity to environmental conditions. Problems in development of a biological control agent based on induced resistance have been described previously (12). There are at least two points in favor of using $B$. sorokiniana as a biocontrol agent. The fungus is cosmopolitan, and it should be possible to find strains endemic to various geographic regions rather than introducing new strains to a region. However, the protective ability of isolates may vary and should be determined before use. Furthermore, the fungus causes necrosis on rice leaves, but does not sporulate on them. This means that there is very little risk for multiplication of the fungus during the growth season and a subsequent transfer of inoculum to the following crops such as wheat and barley. However, because B. sorokiniana is a cosmopolite, such transfer of a little extra inoculum of this organism should not pose any greatly increased risk for the environment.

\section{ACKNOWLEDGMENTS}

This work was financed by Danish International Development Assistance (Danida), Denmark.

\section{LITERATURE CITED}

1. Anonymous. 1976. Guidelines and Rules Relative to Forecast of Occurrence of Disease and Insects Harmful to Crops. Agric. Prod. Bureau JICA, Japan.

2. Anonymous. 1988. Standard Evaluation System for Rice. 3rd ed. International Rice Research Institute, Los Baños, Laguna, Philippines.

3. Arase, S., and Fujita, K. 1992. Induction of inaccessibility to Pyricularia oryzae by pre-inoculation of $P$. grisea in rice leaf-sheath cells. J. Phytopathol. 134:97-102.

4. Bell, D. K., Wells, H. D., and Markham, C. R. 1982. In vitro antagonism of Trichoderma species against six fungal plant pathogens. Phytopathology 72:379-382.

5. Chakraborty, D., and Sinha, A. K. 1984. Similarity between the chemically and biologically induced resistance in wheat seedlings to Drechslera sorokiniana. Z. Pflanzenkr. Pflanzenschutz 91:59-64.

6. Cho, B. H., and Smedegaard-Petersen, V. 1986. Induction of resistance to Erysiphe graminis f. sp. hordei in near-isogenic barley lines. Phytopathology 76:301-305.

7. Fujita, Y., Sonoda, R., and Yaegashi, H. 1990. Leaf blast suppression by pre-inoculation of some incompatible lesion-type isolates of Pyricularia oryzae. Ann. Phytopathol. Soc. Jpn. 56:273-275.

8. Ganguly, D., and Padmanabhan, S. Y. 1962. Helminthosporium disease of rice. IV. Effect of cultural extract of the pathogen on the reaction of rice varieties to the disease. Indian Phytopathol. 15:133-140.

9. Iwano, M. 1987. Suppression of rice blast infection by incompatible strain of Pyricularia oryzae Cav. Bull. Tohoku Natl. Agric. Exp. Stn. 75:27-39.

10. Iwata, M., Iwamatsu, H., Suzuki, Y., Watanabe, T., and Sekizawa, Y. 1982. Inducers of host peroxidase from rice blast fungus. Ann. Phytopathol. Soc. Jpn. 48:267-274.

11. Jørgensen, H. J. L., Andresen, H., and Smedegaard-Petersen, V. 1996. Control of Drechslera teres and other barley pathogens by preinoculation with Bipolaris maydis and Septoria nodorum. Phytopathology 86:602-607.
12. Jørgensen, H. J. L., and Smedegaard-Petersen, V. 1994. Constraints in the implementation of induced resistance against necrotrophic pathogens of cereals. Pages 77-85 in: Biological Control of Fruit and Foliar Disease. Proc. Workshop CEC Prog. "Competitiveness of Agriculture and Management of Agricultural Resources.” (CAMAR), 1993. P. Lepoivre, ed. European Commission. Directorate-General for Agriculture. Working document for the European Commission reference F.II.3-SJ/0010.

13. Kiyosawa, S., and Fujimaki, H. 1967. Studies on mixture inoculation of Pyricularia oryzae on rice. I. Effects of mixture inoculation and concentration on the formation of susceptible lesions in the injection inoculation. Bull. Natl. Inst. Agric. Sci. D 17:1-19.

14. Kloepper, J. W., Tuzun, S., and Kuć, J. A. 1992. Proposed definitions related to induced disease resistance. Biocontrol Sci. Technol. 2:349-351.

15. Mahuku, G. S., Hall, R., and Goodwin, P. H. 1996. Co-infection and induction of systemic acquired resistance by weakly and highly virulent isolates of Leptosphaeria maculans in oilseed rape. Physiol. Mol. Plant Pathol. 49:61-72.

16. Manandhar, H. K. 1987. Rice Diseases in Nepal. Plant Pathol. Div., Dep. Agric. and Winrock International, USAID, Kathmandu, Nepal.

17. Manandhar, H. K. 1996. Rice blast disease: Seed transmission and induced resistance. Ph.D. thesis. The Royal Veterinary and Agricultural University, Copenhagen, Denmark.

18. Manandhar, H. K., Smedegaard-Petersen, V., and Mathur, S. B., 1993. Control of leaf blast (Pyricularia oryzae) of rice by preinoculation with $\mathrm{Bi}$ polaris sorokiniana. Page 212 in: Abstracts. Int. Congr. Plant Pathol., 6th. Canadian Phytopathological Society, Guelph, and National Research Council, Ottawa, Canada.

19. Manandhar, H. K., Thapa, B. J., and Amatya, P. 1985. Efficacy of various fungicides on the control of rice blast disease. J. Inst. Agric. Anim. Sci. (Nepal) 6:21-29.

20. Ohata, K., and Kozaka, T. 1967. Interaction between two races of Piricularia oryzae in lesion-formation in rice plants and accumulation of fluorescent compounds associated with infection. Bull. Natl. Inst. Agric. Sci. C 21:111-135.

21. Ou, S. H. 1985. Rice Diseases. 2nd ed. Commonwealth Mycological Institute, Kew, England.

22. Park, S. K., and Kim, K. C. 1983. Effects of mixing and reciprocal inoculation with compatible and incompatible races of Pyricularia oryzae on the enlargement of disease lesions of rice blast. Korean J. Plant Prot. 22:300-306.

23. Reimmann, C., Hofmann, C., Mauch, F., and Dudler, R. 1995. Characterization of a rice gene induced by Pseudomonas syringae pv. syringae: Requirement for the bacterial lemA gene function. Physiol. Mol. Plant Pathol. 46:71-81.

24. Sarhan, A. R. T., and Kiraly, Z. 1986. Induction of systemic acquired resistance in barley infected with Helminthosporium sativum. Iraqi J. Agric. Sci. "Zanco" (Suppl.) 4:25-31.

25. Sarhan, A. R. T., Király, Z., Sziráki, I., and Smedegaard-Petersen, V. 1991. Increased levels of cytokinins in barley leaves having the systemic acquired resistance to Bipolaris sorokiniana (Sacc.) Shoemaker. J. Phytopathol. 131:101-108.

26. Schaffrath, U., Scheinpflug, H., and Reisener, H. J. 1995. An elicitor from Pyricularia oryzae induces resistance responses in rice: Isolation, characterization and physiological properties. Physiol. Mol. Plant Pathol. 46:293-307.

27. Shen, Y., Huang, D., Qiu, D., Fan, Z., Wang, J., and Yuan, X. 1990. Exploration of induced resistance in rice plants by buff pigment mutants of Pyricularia oryzae. Chin. J. Rice Sci. 4:139-142.

28. Sinha, A. K., and Das, N. C. 1972. Induced resistance in rice plants to Helminthosporium oryzae. Physiol. Plant Pathol. 2:401-410.

29. Sinha, A. K., and Trivedi, N. 1969. Immunization of rice plants against Helminthosporium infection. Nature (Lond.) 223:963-964.

30. Sinha, A. K., and Trivedi, N. 1972. Resistance induced in rice plants against Helminthosporium infection. Phytopathol. Z. 74:182-191.

31. Smedegaard-Petersen, V., and Tolstrup, K. 1985. The limiting effect of disease resistance on yield. Annu. Rev. Phytopathol. 23:475-490.

32. Smith, J. A., and Métraux, J.-P. 1991. Pseudomonas syringae pv. syringae induces systemic resistance to Pyricularia oryzae in rice. Physiol. Mol. Plant Pathol. 39:451-461.

33. Soil Survey Staff. 1994. Keys to Soil Taxonomy. U.S. Dep. Agric. Soil Cons. Serv. 6th ed. Pocahontas Press, Inc., Blacksburg, VA.

34. Sun, G., and Sun, S. 1992. Inducing rice blast (B1) resistance by inoculating with an incompatible race of Pyricularia oryzae Cav. Int. Rice Res. Newsl. 17(5):10-11.

35. Thieron, M., Schaffrath, U., Reisener, H. J., and Scheinpflug, H. 1995. Systemic acquired resistance in rice: Studies on the mode of action of diverse substances inducing resistance in rice to Pyricularia oryzae. Meded. Fac. Landbouwkundige Toegepaste Biol. Wetenschappen Univ. Gent 60(2b):421-429.

36. Trivedi, N., and Sinha, A. K. 1976. Resistance induced in rice plants against Helminthosporium infection by treatment with various fungal fluids. Phytopathol. Z. 86:335-344. 